Vol. 3, Issue I, pp. 24-31, 2021

Available online at: https://tljbm.org/jurnal/index.php/tljbm

\title{
The Impact of Tourist Experience Quality and Involvement on Tourist Recommendation Intention: Evidence From Ramelau Mountain as Tourist Destination in Timor-Leste
}

\author{
Agustinus Nahak Seran ${ }^{a}$, Domingas R. da C. Ximenes ${ }^{a}$, Margaretta Evy M.D. da Silva ${ }^{a}$, Estanislau S. Saldanha ${ }^{b}$ \\ ${ }^{a}$ School of Tourism and Hospitality, Department of Tour and Travel Management, Dili Institute of Technology, Timor-Leste. \\ ${ }^{b}$ Master of Business Administration (MBA) Program, Dili Institute of Technology, Timor-Leste. \\ Email: reissureicao98@gmail.com, agustinusnahakbali@gmail.com,margarettadasilva@yahoo.com, \\ estanislausaldanha@yahoo.com
}

\begin{abstract}
This study aims to test a model linking tourist experience quality, involvement and recommendation intention. The data was collected from 397 tourists as respondents used a five scale likert questionnaires, and SMART-PLS 3.1 was used for data analysis. The result of this research showed that tourist experience quality and involvement positively and significantly influenced on tourist recommendation intention. This study enriches the empirical debates on tourist experience quality, involvement and recommendation intention in emergent tourist destination. Study also provides insight description to the government and tourism industry to improve Ramelau Mountain as tourism destination by providing memorable experience quality and tourism engagement to enhance tourists to revisit and recommend to the other potential tourists to visit Ramelau Mountain.
\end{abstract}

Keywords: Experience Quality, Tourist Involvement, Recommendation Intention, Tourism Destination, Ramelau Mountain, Timor-Leste.

\section{Introduction}

Tourism is a global industry which contributes significantly to the economic growth, sustainable job creation (Chaulagain, Wiitala and Fu, 2019; Ratnasari et al., 2020; Saldanha et al., 2020), cultural and knowledge sharing (Pyke et al., 2019). Tourism destination is considered as a tourism product (Chaulagain, Wiitala and $\mathrm{Fu}, 2019$ ) which is important to enchance tourists experiences and involvement in tourism activities (Lu, Chi and Liu, 2015; Kusumawati and Rahayu, 2020), leading to tourist recommendation intention to visit a tourism destination (Chaulagain, Wiitala and $\mathrm{Fu}, 2019)$. Tourism destination is place offers to visitors enjoy various types of travel experiences such as the uniqueness scenery, blueocean, hiking and enjoy the view of the mountain (Huang et al., 2015; Jiménez-Barreto et al., 2020). Tourism destination must satisfy the expectation of visitors by including insfrastructure and facilities tailored to their needs (Huang et al., 2015; Su et al., 2020).

Tourist experience quality represents how tourist emotionally evaluate their experiences as they participate in consumption activities and interact with the service surroundings, service providers, other customers, customer's companions, and other element (Hasan et al., 2019). Tourist experience quality has become a critical concept in tourist behavior (Jin et al., 2015). Tourists have good experiences in their visit to various tourism destination will lead to positively talk, recommend to other people and revisit the the same destination (Campos et al., 2017; Ratnasari et al., 2020). Therefore, tourists' experience quality has positive impact on tourist recommendation intention (Altunel and Erkut, 2015; Li, Wen and Ying, 2018).
Tourist involvement is an individual and a recreational activity, at one point in time, characterized by some level of enjoyment and self-expression being achieved through the activity (Hwang, Lee and Chen, 2005; Altunel and Erkut, 2015).

Tourist recommendation intention is tourist actions to tell people, share positive information, experienced on tourism destination due to they feel satisfied with tourism destination or represents an individual efforts to obtain the desire goal (Jin et al., 2015). Tourist recommendation intention helps to lead to sustainable visitation in one tourism destination (Zauberman et al., 2009; Li, Wen and Ying, 2018). Previous studies revealed that quality experience influenced positively and significantly on tourist recommentation intentionin (Chen and Chen, 2010; Afonso et al., 2018; Rasoolimanesh et al., 2021), while tourist involvement had no significant impact (Altunel and Erkut, 2015).

Dividing results of previous empirical studies confirm that tourist recommendation which trigger positive feeling, intention to revisit and willing to promote to the other potential tourists to visit the same tourism destination. This also requires undertaking studies to find proper antecedent variables for tourist recommendation intention especially for emergent tourist destination such as Timor-Leste. The objectives of this research are: (1) To analyse and explain the impact of tourists experience quality on tourist recommendation Intention in Ramelau mountain. (2) To analyse and explain the impact of tourist involvement on tourist recommendation intention in Ramelau mountain. 


\section{Theoretical Framework, Research Model and Hypothesis}

\section{1. Tourist Destination}

Tourism destination is basically a geographic areas, which attracts visitors. This can be an individual country or a city. A tourism destination has different types of accommodation and other facilities such as restaurant (Soininen, 2015). Tourism destination are the foundation units of tourism, the term tourism destination is a typical geographical term and is understood as a part of geographical space (Zemla, 2016). Tourism destination is a beautifull and unique place that must satisfy the expectations of visitor by including infrastructure and fasilities that are tailored to their needs (Patandianan and Shibusawa, 2020).

\subsection{Tourist Experience Quality}

Experience quality is a tourist judgement based on his or her evaluation of the overall experience at a tourism destination (Zatori, Smith and Puczko, 2018; Rasoolimanesh et al., 2021). Tourist experience quality can contribute to the tourist's perception of value and satisfaction, which in turn influences of tourist loyality (Moon and Han, 2018). Experience quality is a tourist subjective evaluation on affective responses to their desired social-psychological benefit (Chen and Chen, 2010).

Tourist experience is an important factor in tourism recommendation intention. Tourist will express their positive feelings, which in turns revisit and recommend to other visitors to visit the same tourism destination (Chang, Backman and Huang, 2014). Many tourist destinations try to offer attractive events and products in addition to natural beauty in order to provide memorable events to attract tourists.

Tourism experience quality consists of seven dimensions namely hedonism, novelty, local culture, refreshment, meaningfulness, involvement, and knowledge (Kim, Ritchie and McCormick, 2012). However, this dimension has been criticized as not the experience quality dimensions, but the tourist experience based on their feelings and subjective responses after involving in tourism activities (Quadri-Felitti and Fiore, 2012). Therefore, Fernandes and Cruz (2016) further developed experience quality dimensions (29 items) namely environment, service providers, learning, entertainment, functional benefits, trust, satisfaction, loyalty and advocacy.

\section{2. Tourist Involvement}

Involvement is the positive feeling, choice and control on the service offering, and capacity building which lead to a sense of mutual cooperation (Chen and Chen, 2010; Afonso et al., 2018). Involvement is also known as the degree of individual's partisipation in an organization's desicionmaking which also links to the sense of responsability and commitment (Amah, 2013), or as an individual and a recreational activity resulting in some level of enjoyment and self-expression being achieved through the activity (Hwang, Lee and Chen, 2005). Tourist involvement is defined as the level of importance a tourist attributes to an object, an action, or an activity and the enthusiasm and interest that is generated (Altunel and Erkut, 2015).

\section{3. Tourist Recommendation Intention}

Recommendation is one of the follow-up actions to share to other people about somenting which people felt appreciate and satisfied during involve in some activities. Recommendation intention is a superior predictor of future performance. Recommendation intention must reflect something that is already captured in tourist satisfaction during visiting tourism destinantion (Chang, Backman and Huang, 2014; Altunel and Erkut, 2015; Ratnasari et al., 2020). Recommendation intention is the delivery of application from the result of observations of tourists desire (McGinty and Smith, 2009:36). Destination attractiveness, experience quality and involvement as antecedent variable for tourist loyalty and recommendation intention (Dedeoğlu, 2019; Yin et al., 2020; Rasoolimanesh et al., 2021).

\section{4. Hypothesis}

\subsubsection{Tourist Experience Quality and Tourist Recommendation Intention}

Experience quality is related tourism perception and feelings about a tourism destination after they visit. If tourists have positive feelings, then they will revisit and recommend to other people to visit the same tourism destination (Chang, Backman and Huang, 2014; Cambra-Fierro et al., 2019). Therefore, experience quality has positive impact on tourism recommendation intention. This has been confirmed by study of Kang \& Gretzel (2012) that experience quality has a positive effect on recommendation intention (Rasoolimanesh et al., 2021) through tourists satisfation and appreciation of the places that they visited (Chang, Backman and Huang, 2014; Altunel and Erkut, 2015).

$\mathrm{H}_{1}$ : Tourist experience quality has positive and significant impact on tourist recommendation intention in Ramelau mountain.

\subsubsection{Tourist Involvement and Tourist Recommendation Intention}

Tourism involvement is considered important aspect in tourism planning and development. Tourism involvement secures tourism experience, participation and action toward a tourism destination. Tourist's involvement can contributed to understanding and predicting behaviour intention, decision-making and tourists loyalty to a destination (Campos et al., 2017). Study of Afonso et al. (2018) showed that tourist involvement influence positively and significantly on touristis recommendation intention. 
Vol. 3, Issue I, pp. 24-31, 2021

Available online at: https://tljbm.org/jurnal/index.php/tljbm

$\mathrm{H}_{2}$ : Tourist involvement has positive and significant impact on tourist recommendation intention in Ramelau mountain.

\section{Research Method}

\subsection{Research Population and Sample}

This research was carried out in Nunomogue village, Hatubuilico Post-Administrative, Ainaro Municipality for 2 months, startin from $5^{\text {th }}$ of June to $5^{\text {th }}$ of August 2021. The population of this research is the tourists visited Ramelau Mountain from the year of 2018 to 2020. The total population of the research was 48,018 based on the data from National Directorate Tourist Development in Hatubuilico (2021), while, 397 samples were used after the calculation by using Slovin formula with the marginal error of $5 \%$.

To select research respondents, accidental sampling technique was used. This means that anyone had visited the Ramelau Mauntain is considered as respondent. Therefore, qustionnaires were distributed to respondents in Ramelau Mountain, and Dili. Respondents were assured that their responses will be kept confidential at all the time in order to stimulate respondents'cooperation to fill the questionnares.

\subsection{Measurement}

Experience Quality. Experience quality (EQ) is defined as tourist attraction that can enchance tourists experiences during their visiting in a destination and can play a significant role as contributor to the tourist's perception of value and satisfaction. (EQ) is measured by enjoyment (EQ1), scape (EQ2), tourist attraction (EQ3), amenities (EQ4), accessibility (EQ5), ancillary (EQ6), and social interact (EQ7) adopted from (Altunel and Erkut, 2015) and Pitana (2012).

Tourist Involvement. Tourist Involvement (TI) is defined as tourist participation in tourism activity during visiting in one destination (Afonso et al., 2018) also as a identification existing between an individual and a recreational activity, at one point in time, characterized by some levels of enjoyment and self-expression being achieved through the activity. (TI) is measured by people identification (TI1), self-discovering (TI2), holiday discussion with friends (TI3), tourism activity involvement (TI4) and relatives (TI5) (Altunel and Erkut, 2015).

Recommendation Intention. Recommendation Intention is the follow-up actions to share to other people about somenting which people felt appreciate and satisfied during involve in some activities or visiting a destinantion. It is measured by recommendation to family and friends (RI1), uploading information on social media (RI2) and revisit (RI3) (Altunel and Erkut, 2015).

\subsection{Data Collection and Analysis}

Data collection is a process of collecting information/data from all the relevant sources to look for answers to the research problems, test the hypothesis and evaluation (Jhon Dudovskiy, 2018). The technique of collecting data is using questionnaires of Likert Scale. The reason of using questionaries are because questionaries as effective and efficient methods. The questionnaires were adapted by previous research that related to the topic.

This research used SMART-PLS 3.1 to analyse data in order to test validity and reliability of the model and the relationship between variables following outer and inner model measurement as recommended by Hair et al. (2014). Hypothesis was tested using path coefficient $\mathrm{T}$ and $\mathrm{P}$ Values). The threshold value of $\mathrm{T}$ is higher that 1.96 and $\mathrm{P}$ value is lower than 0.05 (Hair et al., 2017).

\section{Results and Discussions \\ 4.1. Demographic Characteristic}

This research was carried out in Hatubuilico, Ainaro Municipality with the target population of 48,018 tourists and 379 were selected, based on Slovin formula, as respondents for this research. From this, male (48.61\%) and female $(51.39 \%)$. Based on the age, the majority of respondents with the age 18-25 years old (77.01\%), 26-30 years old (18.36\%), 31-37 years old (4.9\%), and 38-50 years old $(1.2 \%)$. From the education level, the majority of respondents from university students $(50.7 \%)$, graduating from high school $(46.3 \%)$ and graduating from the univesity $(3 \%)$. Based on the profession, the majority of respondents from students $(72.54 \%)$, workers $(21.66 \%)$, teachers $(1.51 \%)$ and Members of Soldado Negro Rainha Ramelalu (4.28\%).

\subsection{Validity and Reliability Tests}

The validity test is categorized into two types namely convergent validity and discriminant validity. Convergent validity is measured by utilising two parameters such as indicator loading or outer loading (OL) and average variance extracted (AVE). According to Hair et al., (2014), the item is valid when the OL value is higher than 0.7 , and the AVE value is higher than 0.5 . However, for exploratory research, the OL value can be accepted at 0.6 and the AVE values of all items are above the minimum suggested value of 0.5 . In this research there are some indicators of experience quality (EQ) namely EQ1, EQ2, EQ15, .EQ6, and TI1 in tourist involvement (TI) are invalid due to the OL value of the indicators are below minimal the minimum OL value which influence the content validity (Hair et al., 2014). However, some items such as EQ13, EQ14, EQ17, TI12, TI13, TI14, RI1, RI2 and RI3 are valid to measure inner model (Figure $1)$. 
Vol. 3, Issue I, pp. 24-31, 2021

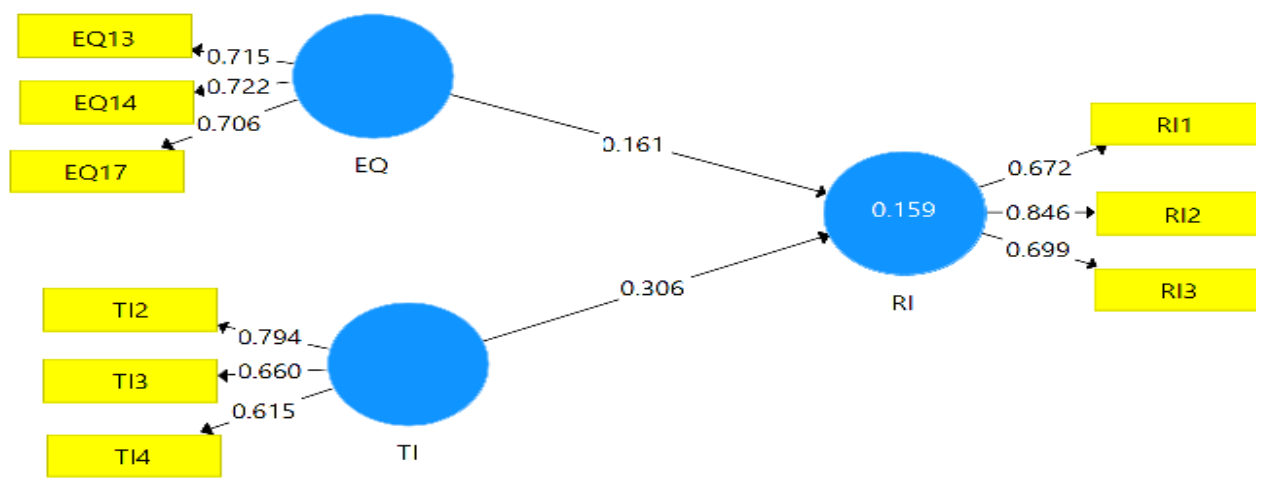

Figure 2. Outer Loading (OL) for Convergent Validity

The discriminant validity is to represent empirical distinct between variable and another variable, all construct measures that is intended to measure (Hopkins, 2015). Discriminant validity was tested by using Fornell-Larcker Criterion, and Heterotrait-Monotrait Ratio (HTMT).

This method shows that variable or construct which has variance value with highest indicators compares to other variable. Therefore, the root average variance extracted (AVE) value of every items are highest square correlation and another variable or constructs as suggested by Hair et al. (2014). Table I shows the values of Fornell-Larcker Criterion all items were fulfilled the criteria which recommended by Hair et al. (2014). That is why; all items are valid based on Fornell-Larcker Criterion (Table I).

Table I. Fornell-Larcker Criterion for Discriminant Validity

\begin{tabular}{|c|c|c|c|}
\hline Item & EQ & RI & TI \\
\hline EQ & 0.714 & & \\
\hline RI & 0.283 & 0.743 & \\
\hline TI & 0.399 & 0.370 & 0.694 \\
\hline
\end{tabular}

Heterotrait-Monotrait Ratio (HTMT) is another parameter to measure discriminant validity of outer model. Normally, the maximum values of HTMT of items are below than 0.9 (Henseler, Ringle and Sarstedt, 2015). Table II showed that the HTMT values of all items were below than 0.9 . Therefore, all items were valid to use in inner model test.

Table II. Heterotrait-Monotrait Ratio for Discriminant Validity

\begin{tabular}{|c|c|c|c|}
\hline Item & EQ & RI & TI \\
\hline \multicolumn{4}{|l|}{ EQ } \\
\hline RI & 0.444 & & \\
\hline TI & 0.791 & 0.687 & \\
\hline
\end{tabular}

Rreliability test is known as the internal consistent of indicators to measure one variable. Normally, the reliability teste is used parameter namely composite reliability (CR). According to (Hair et al., 2014), the item is reliable when the CR values are above the minimum suggested values of 0.7 . In this research, CR values of all items are fulfilling the minimum suggested threshold values 0.7 (Table III). Therefore, all items have good internal consistency.

Table III. Validity (AVE) and Reliability (CA and CR)

\begin{tabular}{|c|c|c|}
\hline Item & $\begin{array}{c}\text { Composite } \\
\text { Reliability } \\
\text { (CR) }\end{array}$ & $\begin{array}{c}\text { Average Variance } \\
\text { Extracted } \\
\text { (AVE) }\end{array}$ \\
\hline EQ & 0.758 & 0.510 \\
\hline RI & 0.785 & 0.552 \\
\hline TI & 0.734 & 0.500 \\
\hline
\end{tabular}

\subsection{Inner Model Test}

This study uses R-square to test the relationship between variables in the inner model. $\mathrm{R}$-square $\left(\mathrm{R}^{2}\right)$ shows the combination the effect of exogenous variables on endogenous variables. Acceptable $\mathrm{R}^{2}$ values are 0.75 (strong model), 0.33 (medium model) and 0.25 (weak model) (Hair et al., 2014; Saldanha et al., 2018). The resul of this study revealed that coefficient of determination or R-square $\left(\mathrm{R}^{2}\right)$ value were 0.159 which could categorized as low relationship (2018) (Table IV).

Table IV. R-Square value

\begin{tabular}{|ccc|}
\hline Item & R Square & $\begin{array}{c}\text { R Square } \\
\text { Adjusted }\end{array}$ \\
\hline RI & 0.159 & 0.154 \\
\hline
\end{tabular}




\subsection{Hypothesis Testing}

The first hypothesis is to test the influence of tourist experience quality on tourist recommendation intention. The results from SMART-PLS 3.0 shows that the T value (2.876) which is far beyond the minimum threshold value of 1.96 and the $P$ value (0.004) is below the maximum threshold value of 0.05 . This indicates that tourist experience quality influenced positively and significantly on tourist recommendation intention in Ramelau mountain. Concequently, $\mathrm{H}_{1}$ was supported (Table V).
The second hypothesis is to test the impact of tourist involvement on tourist recommendation intention. The results of SMART-PLS 3.0 showed that the T value (7.029) which is exceeded the minimum allowable value of 1.96 , and the $\mathrm{P}$ value (0.000) is below the maximum threshold value of 0.05 . This indicates that tourist involvement influence positively and significantly on the tourist recommedantion intention in Ramelau mountain. Concequently, $\mathrm{H}_{2}$ is supported.

Table V. T and P Values for Hypothesis Test (Direct Effect)

\begin{tabular}{|lcccccc|}
\multicolumn{1}{c}{ Construct } & $\begin{array}{c}\text { Original } \\
\text { Sample (O) }\end{array}$ & $\begin{array}{c}\text { Sample } \\
\text { Mean (M) }\end{array}$ & $\begin{array}{c}\text { Standard Deviation } \\
\text { (STDEV) }\end{array}$ & $\begin{array}{c}\text { T Statistics } \\
(|\mathbf{O} / \mathbf{S T D E V}|)\end{array}$ & P Values & Note \\
\hline TEQ -> TRI & 0.161 & 0.168 & 0.056 & 2.876 & 0.004 & Significant \\
TI -> TRI & 0.306 & 0.312 & 0.044 & 7.029 & 0.000 & Significant \\
\hline
\end{tabular}

\subsection{Discussion}

The first objective of this research is to test the impact of tourist experience qulity on tourist recommendation intention in Ramelau Mountain. The result of the research showed that tourist experience qulity has positive and significant impact on tourist recommendation intention. Tourists satisfy to visit Ramelau Mountain to pray, enjoy the originality of the mountain, beautiful natures, and history behind the mountain. Tourist also enjoy with accessibility, basic infrastructures and accommodation and parking places of the site. This has offered tourists to get memorable experience through enjoyment, scape and attractions, which in turns lead them to recommend to their relatives and friends via passing positive information on social media and revisit Rameau Mountain. This confirms that tourists emotionally evaluates their experiences as they participate in consumption activities and interact with the service surroundings, service providers, and customer's companions (Chen and Chen, 2010; Chang, Backman and Huang, 2014). Tourists value destination attractiveness, which lead to trigger revisit intention and promote to the other potential tourists (Afonso et al., 2018; Li, Wen and Ying, 2018; Dedeoğlu, 2019). If tourists have high experience quality in a tourism destination, then they can be motivated to share their positive experience with their friends and families (Cambra-Fierro et al., 2019). The result of the study is in line with the previous studies revealed that tourist experience has positive and significant effect on tourist recommendation intention (Altunel and Erkut, 2015; Li, Wen and Ying, 2018) and tourist loyalty (Fernandes and Cruz, 2016; Wu, Cheng and Ai, 2018; Jiménez-Barreto et al., 2020).

The second objective of this research is to test the impact of tourist involvement on tourist recommendation intention in Ramelau Mountain. The result of the research showed that tourist involvement has impact on tourist recommendation intention. Tourists can involve through hiking the mountain, pray, took photos and look at the awesome scanery. This will encourage tourists to pass positive information on social media, recommend to the other people and revisit Rameau Mountain because tourist's involvement can contributed to understanding and predicting behaviour intention, decisionmaking and tourists loyalty to a destination (Campos et al., 2017). This research showed that tourist involvement has positively impact on touristis recommendation intention to visit Ramelau Mountain, of which it confirms the study of Afonso et al. (2018). However, the result of this study is asymmetric finding to the study of (Altunel and Erkut, 2015) that tourist involvement has insignificant influence on tourism recommendation intention.

\section{Conclusions and Implication}

In this study, the relationships among tourist experience quality, involvement and recommendation intention were examined. The statistic results show that tourist experience quality and involvement influence positively and significantly on tourist recommendation intention. The more tourist involvement in activities in a tourism destination, then that will provide good experience quality, ultimately enhancing tourist intention to recommend to the other people to visit the same tourism destination.

In Ramelau Mountain, tourist experience several activities such as experience the beautiful natural view, hiking, and praying which lead them to enjoy, have positive feelings, and intention to recommend to the other tourists. Tourist involvement can also enhance their knowledge and self-discovering on Ramelau Mountain, which lead them to revisit and share their experiences to the other people via social media, and word of mouth (WOM). 
Vol. 3, Issue I, pp. 24-31, 2021

Available online at: https://tljbm.org/jurnal/index.php/tljbm

Private sector and organization have to work with local community in order to prepara the most principal facilities such as guest house, local restaurant and parking in Ramelau Mountain. It is also important to organize weekly attractions and activities that involve tourists, which aims to offer memorable experience to tourists. This will attract more tourists which then ultimately also provide benefits to government, private sector, tour operator, and local community. Therefore, local community should always be reminded that they are the owner of Ramelau Mountain, and tourism is activities that can contribute to the local economy, job creation, income generation, and knowledge sharing. Therefore, local community participation and collaboration is important to secure the sustainable development of Ramelau Mountain as tourist destination in the future.

\section{Limitation and Future Research}

The results of this study stated that tourist experience quality and invlovement has positively and significantly impact on tourist recommendation intention in Ramelau Mountain, tourism destination. Neverthless, needed to recognize that the research might have various limitations as below: Firstly, this study was only using a single data collection instrumentt is questionaire. That is why, the responses were absolutely depending on respondents which might only provide socially acceptable responses and not reflected the factual answer. Secondly, this research only focused of tourist experience quality and involvement on tourist recommendation intention through natural and religious attraction and activities involvement of tourists. However, experience quality and involvement on tourist recommendation intention in Ramelau mountain can be infuenced by cultural factor, lifestyle of community who lives near the destination and agrotourism. Thirdly, this study is adapted by the previous study of Altunel and Erkut (2015) in Stainbul. The indicators which researcher adapted through added the theory of $4 \mathrm{~A}$ in order to develop the questionnaries and the target result. Unfortunately, some indicators were not valid due to not related to the real situation and tourists perception of the destination. Finally, this study only focused on the perception of the tourists about tourism destination impact to their experience quality and invovlement on recommendation intention in Ramelau Mountain.

\section{References}

Afonso, C., Silva, G.M., Gonçalves, H.M., Duarte, M. (2018) 'The role of motivations and involvement in wine tourists' intention to return: SEM and fsQCA findings', Journal of Business Research, 89(November), pp. 313-321.

Altunel, M. C. and Erkut, B. (2015) 'Cultural tourism in Istanbul: The mediation effect of tourist experience and satisfaction on the relationship between involvement and recommendation intention', Journal of Destination Marketing and Management, 4(4), pp. 213-221.

Amah, E., Daminabo, W., Mildred (2013). Corporate Culture: A tool for control and effectiveness in organization. Journal of Maunusizities and Social Science Vol 3, No. 15.

Campos, A. C., Mendes, J., Valle, P.O. do, Scott, N. (2017) 'Cocreating animal-based tourist experiences: Attention, involvement and memorability', Tourism Management, 63, pp. $100-114$.

Cambra-Fierro, J., Xuehui Gao, L., Melero-Polo, I., \& Javier Sese, F. (2019). What drives consumers' active participation in the online channel? Customer equity, experience quality, and relationship proneness. Electronic Commerce Research and Applications, 35(April).

Chang, L. L., Backman, K. F. and Huang, Y. C. (2014) 'Creative tourim: a preliminary examination of creative tourists' motivation, experence, perceived value and revisit intention', International Journl of Culture, Tourism, and Hospitality Research, 8(4), pp. 401-419.

Chaulagain, S., Wiitala, J. and Fu, X. (2019) 'The impact of country image and destination image on US tourists' travel intention', Journal of Destination Marketing and Management, pp. $1-11$.

Chen, C. F. and Chen, F. S. (2010) 'Experience quality, perceived value, satisfaction and behavioral intentions for heritage tourists', Tourism Management, 31(1), pp. 29-35.

Dedeoğlu, B. B. (2019) 'Shaping tourists' destination quality perception and loyalty through destination country image: The importance of involvement and perceived value', Tourism Management Perspectives, 29(June 2018), pp. 105-117.

Dudovskiy, Jhon. (2018 ). The ultimate guide to writing a dissertation in business studies: A step bu step assistance. USA : Perason Education Limited.

Fernandes, T. and Cruz, M. (2016) 'Dimensions and outcomes of experience quality in tourism: The case of Port wine cellars', Journal of Retailing and Consumer Services, 31, pp. 371-379.

Finn, A., Wang, L., Frank, T. (2009). Attribute Perceptions, customer satisfaction and intention to recommend E-Services. University of Alberth School of Business. Canada.

Hair, J., Hollingsworth, C.L.,Randolph, A.B.,Chong, A.Y.L. (2017) 'An updated and expanded assessment of PLS-SEM in information systems research', Industrial Management \& Data Systems, 117(3), pp. 442-458.

Hair, J.F. Sarstedt, M., Hopkins, L., Kuppelwieser, V.G. (2014) 'Partial least squares structural equation modeling (PLS-SEM)', European Business Review, 26(2), pp. 106-121. 
Hair, J.F., Hult, G.T.M., Ringle, C.M., Sarstedt, M. (2014) Partial Least Squares Structural Equation Modeling (Pls-Sem). London: SAGE Publication LTD.

Hasan, M. K., Abdullah, S.K., Lew, T.Y., Islam, M.F. (2019) 'The antecedents of tourist attitudes to revisit and revisit intentions for coastal tourism', International Journal of Culture, Tourism, and Hospitality Research, 13(2), pp. 218-234.

Henseler, J., Ringle, C. M. and Sarstedt, M. (2015) 'A new criterion for assessing discriminant validity in variance-based structural equation modeling', Journal of the Academy of Marketing Science, 43(1), pp. 115-135.

Hopkins, L. (2015) 'Partial least squares structural equation modeling ( PLS-SEM ) An emerging tool in business research', European Business Review, 26(2), pp. 106-121.

Huang, H., Lunhua Mao, L., Wang, J., Zhang, J.J. (2015) 'Assessing the relationships between image congruence, tourist satisfaction and intention to revisit in marathon tourism: the Shanghai International Marathon', International Journal of Sports Marketing and Sponsorship, 16(4), pp. 46-66.

Hwang, S. N., Lee, C. and Chen, H. J. (2005) 'The relationship among tourists' involvement, place attachment and interpretation satisfaction in Taiwan's national parks', Tourism Management, 26(2), pp. 143-156.

Jiménez-Barreto, J., Rubio, N., Campo, S., Molinillo, S. (2020) 'Linking the online destination brand experience and brand credibility with tourists' behavioral intentions toward a destination', Tourism Management.

Kim, J. H., Ritchie, J. R. B. and McCormick, B. (2012) 'Development of a scale to measure memorable tourism experiences', Journal of Travel Research, 51(1), pp. 12-25.

Kusumawati, A. and Rahayu, K. S. (2020) 'The effect of experience quality on customer perceived value and customer satisfaction and its impact on customer loyalty', TQM Journal, 32(6), pp. 1525-1540.

Li, F., Wen, J. and Ying, T. (2018) 'The influence of crisis on tourists' perceived destination image and revisit intention: An exploratory study of Chinese tourists to North Korea', Journal of Destination Marketing and Management, pp. 104-111.

Lu, L., Chi, C. G. and Liu, Y. (2015) 'Authenticity, involvement, and image: Evaluating tourist experiences at historic districts', Tourism Management, 50, pp. 85-96.

McGinty, L.; Smith, B. 2009. On the role of diversity in conversation recommendation system. In Proceedings of the 5th international conference on Case-based reasoning: Research and Development. Springer-Verlag, Berlin.
Patandianan, Marly Valentina:; Shibusawa, Hiroyuki. 2020. Importance and performance of streetscapes ata a tourism destination. Toyohashi University of Technology, Toyohashi, Japan.

Pyke, J., Pyke, S., \& Watuwa, R. (2019). Social tourism and well-being in a first nation community. Annals of Tourism Research, 77, 38-48.

Quadri-Felitti, D. and Fiore, A. M. (2012) 'Experience economy constructs as a framework for understanding wine tourism', Journal of Vacation Marketing, 18(1), pp. 3-15.

Rasoolimanesh, S. M., Seyfi, S., Hall, C.M., Hatamifar, P. (2021) 'Understanding memorable tourism experiences and behavioural intentions of heritage tourists', Journal of Destination Marketing and Management. 21 (2021), 100621.

Ratnasari, R. T., Gunawan, S., Mawardi, S., Mawardi, I., and Kirana, K.C., (2020) 'Emotional experience on behavioral intention for halal tourism', Journal of Islamic Marketing, 12(4), pp. 864-881.

Saldanha, E. D. S., Rahyuda, I.K., Yasa, N.N.K, Sukaatmadja, I.P.G. (2018) 'The Role of Business Strategy in Mediating the Relationship Between Industrial Competition and Performances: A Study in the Higher Education Industry in Timor-Leste', European Journal of Business and Management, $10(8)$, pp. $152-172$.

Saldanha, E. S., Santos, V. Dos, Piedade, S. D. R., Seran, A. N., \& Freitas, J. R. (2020). The Effects of Responsible Tourism on the Quality of Life of Community in Tourism Destination of Com Village. Timor Leste Journal of Business and Management, 2(2), 21-29.

Soininen, Mira. 2015. Development of a tourism destination, case: Erbil Capital of Kurdistan, Iraq.

Su, D. N., Nguyen, N.A.N., Nguyen, Q.N.T., and Tran, T.P. (2020) 'The link between travel motivation and satisfaction towards a heritage destination: The role of visitor engagement, visitor experience and heritage destination image', Tourism Management Perspectives. doi: 10.1016/j.tmp.2020.100634.

Wu, H. C., Cheng, C. C. and Ai, C. H. (2018) 'A study of experiential quality, experiential value, trust, corporate reputation, experiential satisfaction and behavioral intentions for cruise tourists: The case of Hong Kong', Tourism Management, pp. 200-220.

Yin, J., Chemg, Y., Bi, Y., Ni, Y. (2020) 'Tourists perceived crowding and destination attractiveness: The moderating effects of perceived risk and experience quality', Journal of Destination Marketing and Management, 18(September), 100489.

Zatori, A., Smith, M. K. and Puczko, L. (2018) 'Experienceinvolvement, memorability and authenticity: The service 
provider's effect on tourist experience', Tourism Management, 67, pp. 111-126.

Zauberman, G.; Ratner, R.; \& Kim, B. 2009. Memories as assets : Strategic memory protection in choice over timer.Journal of cosumer research, 35 (5), 715-728.

Zemla, Michal. 2016. Tourism Destination : The Networking approach. Pedagogical Universitu of Cracow. 